\title{
The role of myoglobin in epithelial cancers: Insights from transcriptomics
}

\author{
ANNE BICKER $^{1}$, THERESA NAUTH $^{1}$, DANIELA GERST ${ }^{2}$, MOSTAFA AHMED ABOOUF $^{2}$, \\ JOACHIM FANDREY ${ }^{3}$, GLEN KRISTIANSEN ${ }^{4}$, THOMAS ALEXANDER GORR ${ }^{2 *}$ and THOMAS HANKELN ${ }^{1 *}$ \\ ${ }^{1}$ Institute of Organismic and Molecular Evolution, Molecular Genetics and Genome Analysis, \\ Johannes Gutenberg University, D-55099 Mainz, Germany; ${ }^{2}$ Institute of Veterinary Physiology, \\ Vetsuisse Faculty, University of Zurich, CH-8057 Zurich, Switzerland; ${ }^{3}$ Institute of Physiology, \\ University of Duisburg-Essen, D-45147 Essen; ${ }^{4}$ Institute of Pathology, Center for Integrated Oncology, \\ University Hospital Bonn, University of Bonn, D-53127 Bonn, Germany
}

Received August 8, 2019; Accepted November 8, 2019

DOI: 10.3892/ijmm.2019.4433

\begin{abstract}
The muscle-associated respiratory protein myoglobin (MB) is expressed in multiple types of cancer, including breast and prostate tumors. In Kaplan-Meier analyses of the two tumor types, MB positivity is associated with favorable prognoses. Despite its well-characterized function in myocytes, the role of $\mathrm{MB}$ in cancer remains unclear. To study the impact of endogenous MB expression, small interfering RNA MB-knockdown cells were engineered using breast, prostate and colon cancer cell lines (MDA-MB468, LNCaP, DLD-1), and their transcriptomes were investigated using RNA-Seq at different oxygen levels. In MB-positive cells, increased expression of glycolytic genes was observed, which was possibly mediated by a higher activity of hypoxia-inducible factor $1 \alpha$. In addition, the results of the gene set enrichment analysis suggested that MB contributed to fatty acid transport and turnover. MB-positive, wild-type-p53 LNCaP cells also exhibited increased expression of p53 target genes involved in cell cycle checkpoint control and prevention of cell migration. MB-positive cells expressing mutant p53 exhibited upregulation of genes associated with prolonged cancer cell viability and motility. Therefore, it was hypothesized that these transcriptomic differences may result from MB-mediated generation of nitric oxide or reactive oxygen species, thus employing established enzymatic activities of the globin. In summary, the transcriptome comparisons identified potential
\end{abstract}

Correspondence to: Professor Thomas Hankeln, Institute of Organismic and Molecular Evolution, Molecular Genetics and Genome Analysis, Johannes Gutenberg University, 30a J. J. Becherweg, D-55099 Mainz, Germany

E-mail: hankeln@uni-mainz.de

${ }^{*}$ Contributed equally

Key words: myoglobin, hypoxia, breast cancer, prostate cancer, colon cancer, RNA-Seq molecular functions of MB in carcinogenesis by highlighting the interaction of $\mathrm{MB}$ with key metabolic and regulatory processes.

\section{Introduction}

The red color of the vertebrate skeletal and cardiac muscles originates from a high expression level of the respiratory protein myoglobin (MB) $(1,2)$. The globin fold of MB harbors an iron-containing heme group that allows the binding of gaseous ligands such as $\mathrm{O}_{2}$ and nitric oxide (NO) $(3,4)$. The impact of $\mathrm{MB}$ as an intracellular $\mathrm{O}_{2}$ storage and transport molecule was indirectly evidenced when the viability of $\mathrm{Mb}^{-/}$ mice required compensatory adaptions in cardiac and striated muscles, including increased vessel densities, higher blood viscosity and elevated expression of the hypoxia-inducible transcription factors hypoxia-inducible factor $1 \alpha$ (HIF $1 \alpha)$ and HIF2 $\alpha$ (5-7). An additional function of oxygenated MB (oxy-MB) in aerobic muscles is to convert harmful NO to inert nitrate by enzymatic dioxygenase activity $(4,8) . \mathrm{Mb}^{-/-}$mice exhibited a greater sensitivity for altered $\mathrm{NO}^{\circ}$ concentrations in cardiomyocytes compared with respective wild-type animals and were more susceptible to $\mathrm{NO}$-induced changes in the vascular tone, cardiac functions and energetic parameters (8). Oxy-MB was further reported to scavenge toxic reactive oxygen species (ROS) for cell protection in C2C12 mouse myotubes and in the brain of the common carp (9-11). Under hypoxia, deoxygenated MB (deoxy-MB) can produce NO, as observed in studies on mouse smooth muscle cells in vivo; this regulates $\mathrm{NO}^{-}$-mediated vasodilation of adjacent blood vessels in isolated hearts of $\mathrm{Mb}^{+/+}$vs. $\mathrm{Mb}^{-/-}$mice, thus reducing ischemia-induced cardiac damage (12). MB harbors various fatty acid binding sites with high affinity for palmitic and oleic acid (13-15). Thus, oxy-MB has been proposed to bind and transport fatty acids (FAs) and acylcarnitines to mitochondria in an $\mathrm{O}_{2}$-dependent manner $(14,15)$. In addition, since the cardiomyocytes of $\mathrm{Mb}^{-/-}$mice were less able to oxidize fatty acids, older mice developed a lipid overload phenotype that impaired the heart function $(16,17)$. These results suggested that oxy-MB may serve a non-canonical role by promoting FA turnover in vivo. 
Ectopic MB expression at a level of 1:100-1:1,000 compared to striated muscle was further reported in several tumor types, including breast, prostate, non-small lung and colon cancer, renal cell carcinoma, head and neck squamous cell carcinoma, osteosarcoma and leukemic bone marrow (18-25). Instead of using the myocytic standard gene promoter, $M B$ is transcribed from an alternative upstream promoter region in cancer cells, which can be specifically induced by hypoxia and silenced by hormonal treatments $(26,27)$. In addition, MB staining was enhanced at hypoxic, perinecrotic central areas in avascular, non-invasive ductal carcinoma in situ (DCIS) breast tumors (28). Compared to the low-level expression of MB in the healthy breast epithelium, MB production in mammary malignancies increases up to 350-fold (29). Overall, MB positivity was detected in $\sim 40 \%$ of primary breast tumors, mainly in a mosaic-like pattern in luminal-type, estrogen receptor (ER)-positive cases (21), and in $~ 53 \%$ of prostate cancer tumors, mostly in androgen-receptor positive and poorly differentiated cases (24). Kaplan-Meier survival analyses of a large cohort of patients with mammary carcinoma associated high MB expression with beneficial prognostic outcomes for cases with positive or negative ER $\alpha$ receptor status (21). Additionally, a trend towards prolonged recurrence-free patient survival was observed for MB-positive compared with -negative tumors in a cohort of poorly differentiated prostate tumors (24). In contrast to a hypothetical tumor-suppressing role of MB in these tumor entities, patients with lung adenocarcinoma with high MB levels in tumor biopsies exhibited poor prognostic outcomes (22). This discrepancy indicates potential tumor type-specific differences for the role of MB in cancer cells.

Despite a limited number of initial experiments, no in-depth characterization of the molecular role of MB endogenously expressed in tumor cells has been achieved. As breast, prostate and colon cancer exhibit several pathological and biochemical commonalities, and in order to assess a broader spectrum of potential molecular functions of MB in epithelial cancers, the present study aimed to determine the impact of endogenous MB expression in three different cancer cell lines representing the above malignancies: MDA-MB468, LNCaP and DLD-1. To keep this approach free of a priori hypotheses, transcriptome-wide cDNA sequencing (RNA-Seq) of MB-expressing $\left(M B^{+}\right)$cancer cell lines and respective RNA interference (RNAi)-mediated $M B$-knockdown cells (si $M B$ ) was conducted. The bioinformatic identification of differentially expressed gene categories and pathways may provide valuable information about the molecular role of MB in tumor cells.

\section{Materials and methods}

Cell culture. MDA-MB468 and DLD-1 cells were cultured in DMEM/HamsF12 with L-glutamine (PAA Laboratories; GE Healthcare Bio-Sciences Austria GmbH); LNCaP cells were cultured in RPMI-1640 medium with L-glutamine (Invitrogen; Thermo Fisher Scientific, Inc.). All cells were supplemented with $10 \%$ Fetal Bovine Serum Gold (PAA Laboratories; GE Healthcare Bio-Sciences Austria GmbH). Hera cell 240 (MultiTemp Scientific AG), IG150 (Jouan; Thermo Fisher Scientific, Inc.) and CB 53 (Binder $\mathrm{GmbH}$ ) incubators were used for cell culture. For normoxic conditions, cells were cultured in room air with $5 \% \mathrm{CO}_{2}$, whereas hypoxic incubation was conducted with $1 \% \mathrm{O}_{2}$ and $5 \% \mathrm{CO}_{2}$; both at $37^{\circ} \mathrm{C}$ in $\mathrm{H}_{2} \mathrm{O}$-saturated atmosphere. MDA-MB468, DLD-1 and LNCaP cells were authenticated by SNP typing (Multiplexion $\mathrm{GmbH}$ ) and approved for mycoplasma negativity using the VenorGeM Mycoplasma PCR detection kit (Minerva Biolabs $\mathrm{GmbH}$ ) prior to experiments. Transient $M B$-knockdown cells for all three cell lines were generated using small interfering (si)RNA. Cells at 50-60\% confluency were seeded in 24-well plates. After $24 \mathrm{~h}$ of incubation, 20 pmol MB siRNA (HS MB_6, 2607575; anti-sense sequence, 5'-UGAUUAAUCAGA CAAUUGCTA-3'; Qiagen GmbH) or scrambled (scr) RNA (cat. no. 1022076; Qiagen $\mathrm{GmbH}$ ) were diluted in Opti-MEM (cat. no. 31985062; Thermo Fisher Scientific, Inc.) for each well. Lipofectamine ${ }^{\circledR} 2000(1 \mu \mathrm{l}$; Thermo Fisher Scientific, Inc.) was added to $50 \mu \mathrm{l}$ Opti-MEM and incubated for $5 \mathrm{~min}$ at room temperature. The two prepared solutions were then gently mixed together and incubated for $20 \mathrm{~min}$ at room temperature. The oligomer-Lipofectamine 2000 complexes were then added to the cells. After $24 \mathrm{~h}$ of incubation, the culture medium was changed.

RNA-Seq experiments. Following $72 \mathrm{~h}$ of incubation under $1 \% \mathrm{O}_{2}$ or normoxia, RNA was extracted from cells using the RNeasy Mini kit (Qiagen $\mathrm{GmbH}$ ), including the RNase-Free DNase I treatment (Qiagen $\mathrm{GmbH}$ ) for DNA digestion. RNA integrity was confirmed using the Agilent RNA 6000 Nano kit on a 2100 Bioanalyzer (Agilent Technologies $\mathrm{GmbH}$ ). RNA samples from four replicate cell passages were pooled for each condition and cell line. Illumina TruSeq Total RNA transcriptome libraries (Illumina, Inc.) were generated for the pools of the si $M B$ cell types ( 3 cell lines and $2 \mathrm{O}_{2}$ conditions) and the respective $\mathrm{MB}^{+}$controls (StarSEQ GmbH). The $50 \mathrm{bp}$ single-end Illumina sequencing was performed by the next generation sequencing core facility of the Biology Department of Johannes Gutenberg University (Mainz, Germany) on an Illumina HiSeq2500 sequencing platform.

Data processing. Using the CLC Genomics Workbench 8.0.1 sequence trimmer (Qiagen $\mathrm{GmbH}$ ), 12 terminal nucleotides from the 5 ' end, remaining Illumina adapters and low-quality sequences (below Phred 13) were removed from each read. The minimum sequence length was set to $15 \mathrm{bp}$, allowing $\leq 2$ ambiguous nucleotides per read. The reads were then mapped to the annotated human genome hg19 (ftp.ensembl. org/pub/release-75/gtf/homo_sapiens/Homo_sapiens.GRCh37.75. gtf.gz) with the CLC Genomics Workbench 8.0.1 RNA-Seq tool. Mapping parameters were set as default, but included intergenic regions and allowed $\leq 10$ hits per read. Paired two-group comparisons were conducted between the mapping results of $\operatorname{si} M B$ and $\mathrm{MB}^{+}$cells for the three cell lines with or without hypoxia using the CLC Genomics Workbench 8.0.1 with the original reads per kilobase of transcript per million mapped reads (RPKM) values (30). Proportion-based statistics were calculated with Kal's Z-tests [Bonferroni- and false discovery rate (FDR)-corrected] to identify statistically significant differentially expressed genes at $\left[-\log _{10}(\mathrm{p})\right] \geq 0.5(31)$.

Variant detection. Low frequency variant detection was performed with the CLC Genomics Workbench 8.5.1 at default 


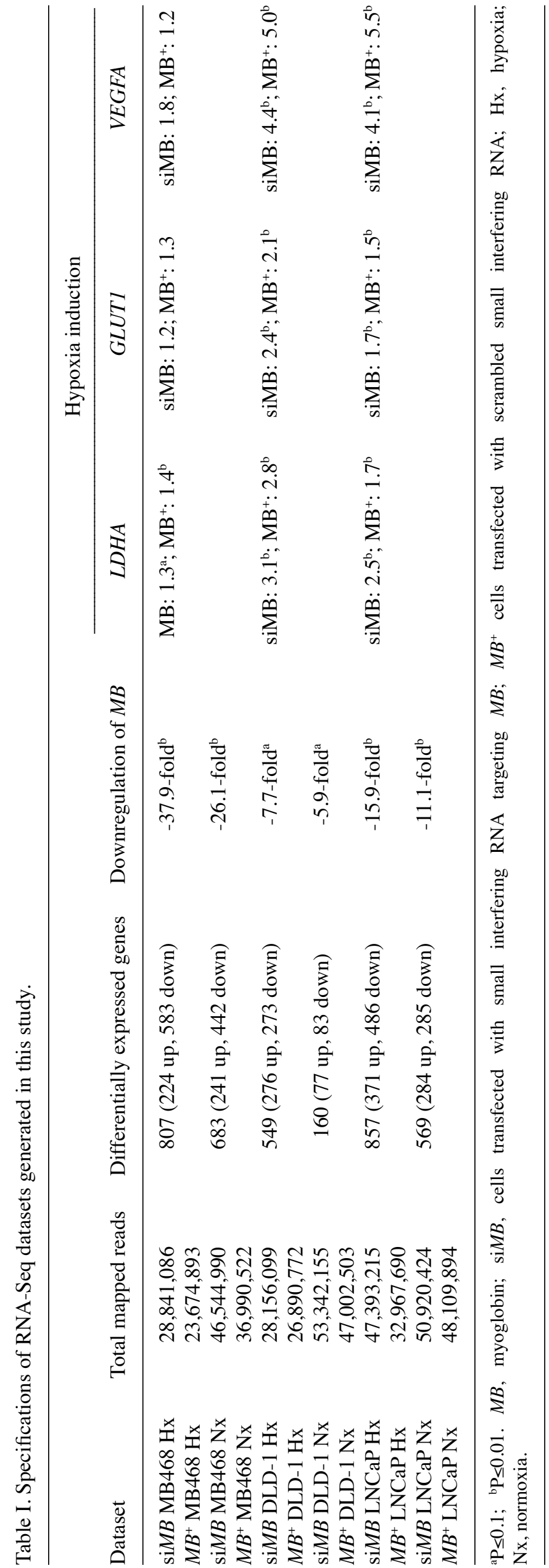


parameters using a minimum read count of 6 , a minimum coverage of six reads and including a read direction filter of $1 \%$. Only variants of QUAL $\geq 100$ (probability that a particular variant exists $\geq 0.9999999999$ ) were listed and annotated with human genome hg19 gene track overlap information to infer potential non-synonymous amino acid changes.

Interpretation of RNA-Seq data. To access the transcriptomewide effects of MB expression in epithelial cancer cells, all genes that were differentially expressed between si $M B$ and $M B^{+}$cells were identified (Table I). A list of genes that were differentially expressed depending on the MB status in at least four of the six gene lists was compiled to filter general MB functions common to the majority of the investigated cell types. This merged gene list was used for gene set enrichment analysis (hypergeometric tests; FDR-corrected $\mathrm{P}<0.05$ ) using the Cytoscape 3 application BiNGO 3.0.3 (32) to generate a map of significantly overrepresented Gene Ontology (GO)-categories.

For a more detailed analysis of the impact of MB in each cell line under each $\mathrm{O}_{2}$ condition, the six lists of genes differentially expressed between si $M B$ and $M B^{+}$cells in matching conditions were further analyzed for GO term enrichment $(\mathrm{P}<0.05)$ and gene enrichment in KEGG and Biocarta pathways using the DAVID Bioinformatics Resources 6.7 functional annotation tool $(33,34)$, choosing either the upregulated or downregulated genes as inputs. Genes differentially expressed between si $M B$ and $\mathrm{MB}^{+}$cells were further annotated and interpreted by Core Ingenuity Pathway analysis (IPA) (http://www.ingenuity.com). Analyses were conducted using the fold-changes determined by CLC two-group-comparisons, including the IPA a priori knowledge of direct and indirect relationships between genes observed in all human tissues. For visualization, a list of significantly active upstream regulators in each condition was compiled based on the direction of regulation of their target genes.

\section{Results}

RNA-Seq data generation. To investigate the function of endogenously expressed $M B$ in epithelial cancer cells, siRNA was used to generate $M B$-knockdown breast (MDA-MB468), prostate (LNCaP) and colon (DLD-1) cancer cells, and their transcriptome profiles were compared to those of matching $M B$-wild-type cells treated with scr siRNA as a control. Different tumor types were selected for studying $M B$ expression to discriminate tumor-specific effects [e.g., ER status (27)] from common changes that may be associated with $M B$ expression throughout different tumor types of epithelial origin. As MB can be either oxygenated or deoxygenated, experiments for all three cell lines were conducted in room air (normoxia) and $1 \% \mathrm{O}_{2}$ (hypoxia), the latter causing a fractional $\mathrm{MB} \mathrm{O}_{2}$ desaturation of $\sim 42 \%$ (35). To specifically study the impact of $M B$ in cells adapted to long-term hypoxia, mimicking tumors, the cells were incubated for $72 \mathrm{~h}$ at hypoxic vs. normoxic conditions; previous experiments on MDA-MB468 siRNA MB-knockdown cells demonstrated strong phenotypic effects at $72 \mathrm{~h}$ (28). Using Illumina transcriptome sequencing and read mapping to the annotated human genome, gene expression profiles were generated for each cell line and condition.
The numbers of successfully mapped reads ranged between 23.7 and 53.3 Mio (Table I).

Functional annotation of differentially regulated genes. Following RNAi, $M B$ was downregulated 6- and 8-fold in DLD-1, 11- and 16-fold in LNCaP and 26- and 38-fold in MDA-MB468 cells compared with the control cells in normoxic and hypoxic conditions, respectively. In addition, between 160 and 857 genes were differentially expressed between siMB and $\mathrm{MB}^{+}$control cells under equivalent oxygen conditions (Tables I and SI). This divergence implied differences in the impact of MB on specific epithelial cell lines and encouraged the investigation of the generic and cell-type specific effects of MB expression in epithelial cancer cells. Differentially expressed genes were subjected to GO term analysis, and overrepresentations of GO terms within gene lists were statistically evaluated.

The effects of MB expression common among the three epithelial cancer cell lines were summarized by BiNGO analysis of a subset of 145 genes, which were consistently differentially expressed in at least four of the six experimental groups (Table I). A number of overrepresented GO terms, presented as colored nodes in Fig. 1, were associated with metabolic shifts (i.e., 'glycolysis', 'fatty acid biosynthetic process', 'oxidative phosphorylation' and 'generation of precursor metabolites and energy') and anti-apoptotic cell signaling (i.e., 'anti-apoptosis', 'negative regulation of programmed cell death' and 'regulation of DNA damage response', signaling transduction by p53 class mediator'). These terms were linked to the overrepresented nodes 'cell cycle' and 'protein ubiquitination' in the BiNGO graph. In addition, overrepresentation of the GO categories 'response to hypoxia', 'response to oxidative stress' and 'response to ROS' was observed, suggesting that MB also participates in cellular response to oxidative stress.

The present study further aimed to identify individual cell type- and $\mathrm{O}_{2}$ level-specific characteristics in the three cancer cell lines (Table II). GO term and KEGG and Biocarta pathway enrichment analyses were performed separately for each subset of significantly upregulated and downregulated genes to compare si $M B$ and $M B^{+}$cells (Table SI). Lists of enriched GO terms revealed a number of categories that repeatedly appeared across all studied cell types. These functional terms were related to those identified before in the global BiNGO analysis. In addition, the terms were linked to a range of known molecular functions exerted by MB. Several GO categories unique either to a certain cell type or to the $\mathrm{O}_{2}$ level were also identified (Table II).

GO terms indicate a metabolic shift in siMB cells. In prostate and breast cancer cells, the GO categories 'response to $\mathrm{O}_{2}$ levels' and 'response to hypoxia' were overrepresented in the set of downregulated genes in si $M B$ cells independent of the $\mathrm{O}_{2}$ conditions (Table II). Since these genes included a number of known hypoxia marker genes (Table SI), these results suggested that MB may modulate the cellular hypoxia response in breast and prostate cancer cell lines.

GO enrichment analysis further indicated a metabolic shift towards a reduced rate of glycolysis in $M B$-knockdown prostate and breast cancer cells under the two $\mathrm{O}_{2}$ conditions. This was evidenced by the downregulation of the hypoxia-regulated 


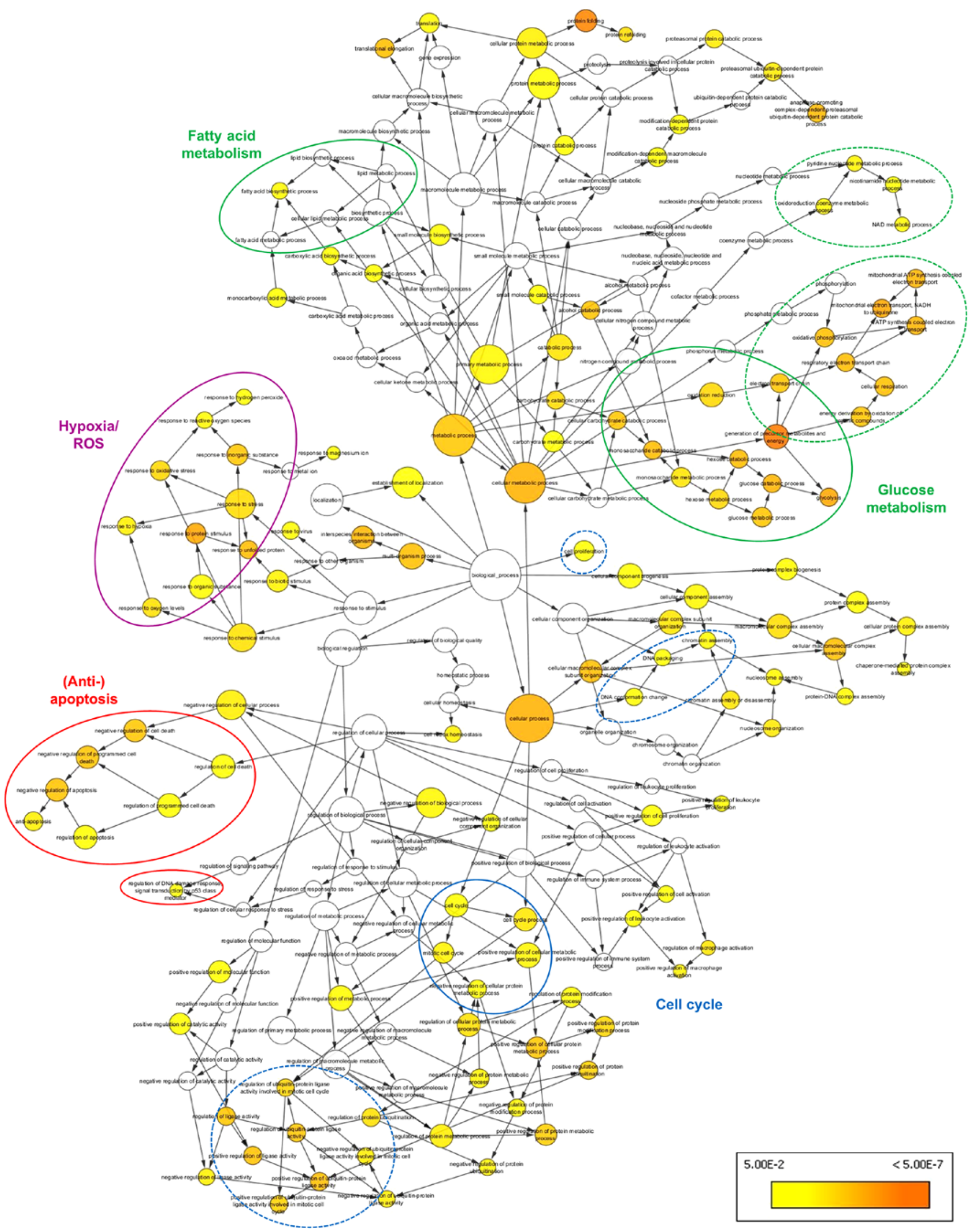

Figure 1. BiNGO graph of genes differentially expressed between cells transfected with siRNA targeting myoglobin or scrambled siRNA. Genes common to at least four experimental groups with matching cell type and $\mathrm{O}_{2}$ conditions were included. Node size represents the number of genes associated with the respective GO term. Yellow nodes represent GO categories significantly overrepresented at $\mathrm{P}<0.05$. Color intensity of the nodes increases with decreasing P-values. Blue and dashed blue lines highlight cell cycle associated terms; green and dashed green lines highlight metabolism-associated terms; the purple circle highlights hypoxia and ROS terms; red lines highlight terms associated with apoptosis. siRNA, small interfering RNA; GO, Gene Ontology; ROS, reactive oxygen species. 







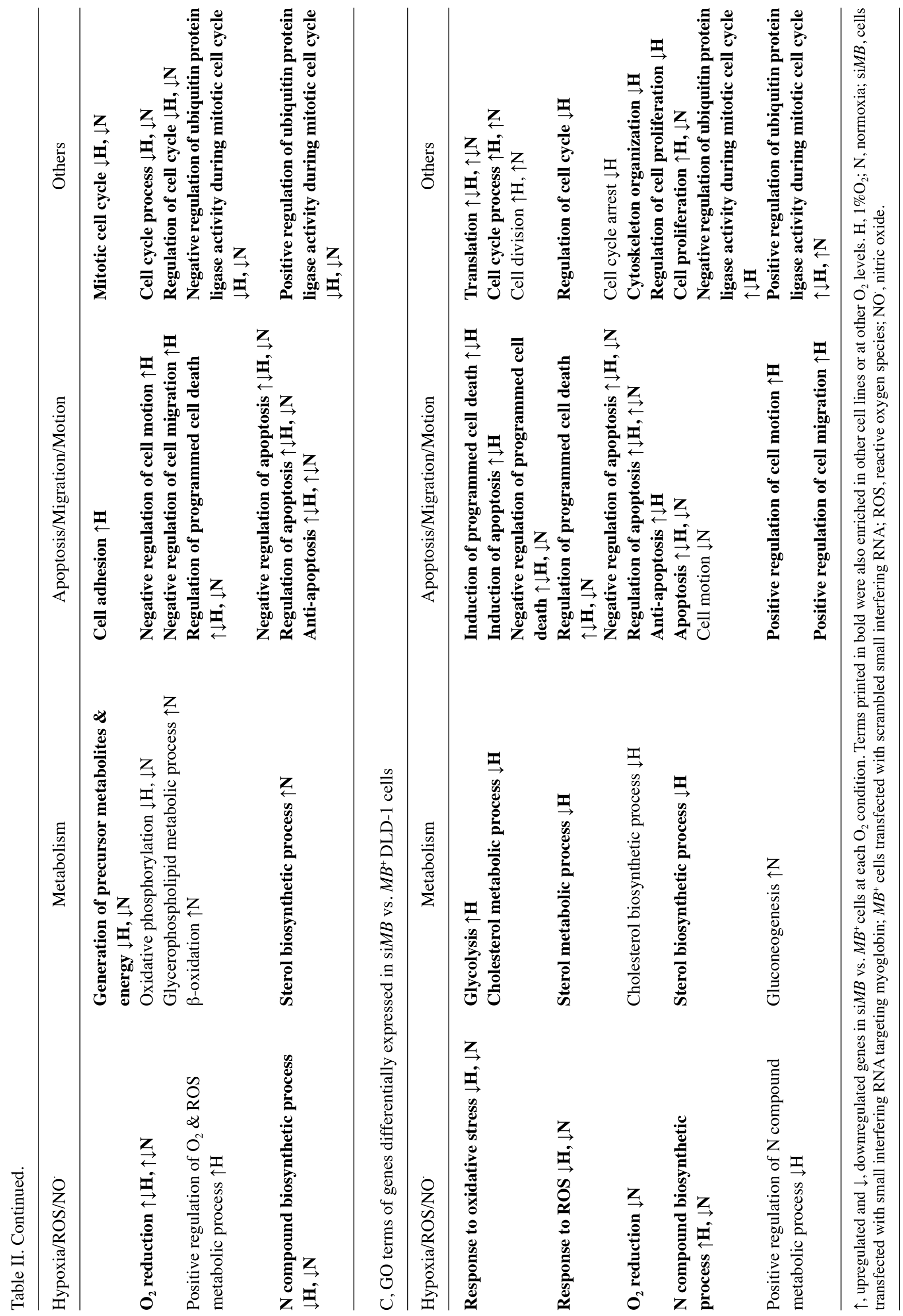




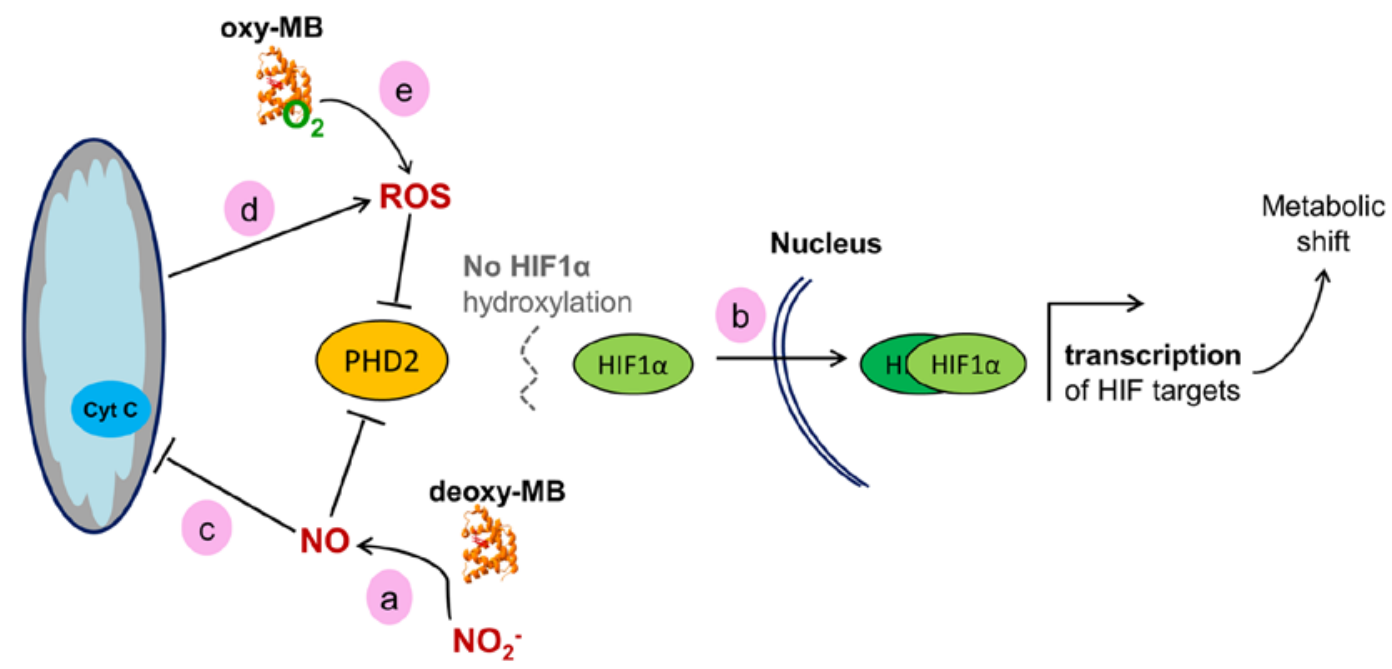

Figure 2. Working model of the hypothetical effects of MB on HIF1 $\alpha$ signaling in cancer cells. (a) Deoxy-MB may increase cellular NO levels to improve HIF1 $\alpha$ stability via PHD2 inactivation. (b) Active HIF1 $\alpha$ enters the nucleus to dimerize with HIF1 $\beta$ and drive target gene expression. (c) NO generated by MB may inhibit the mitochondrial respiratory chain, (d) which would result in increased ROS levels. ROS may also block PHD2 and stimulate HIF signaling. (e) Oxy-MB may release ROS under hypoxia to indirectly enhance the HIF1 $\alpha$ response. MB, myoglobin; HIF, hypoxia-inducible factor; PHD2, prolyl-hydroxylase 2; $\mathrm{NO}$, nitric oxide; ROS, reactive oxygen species.

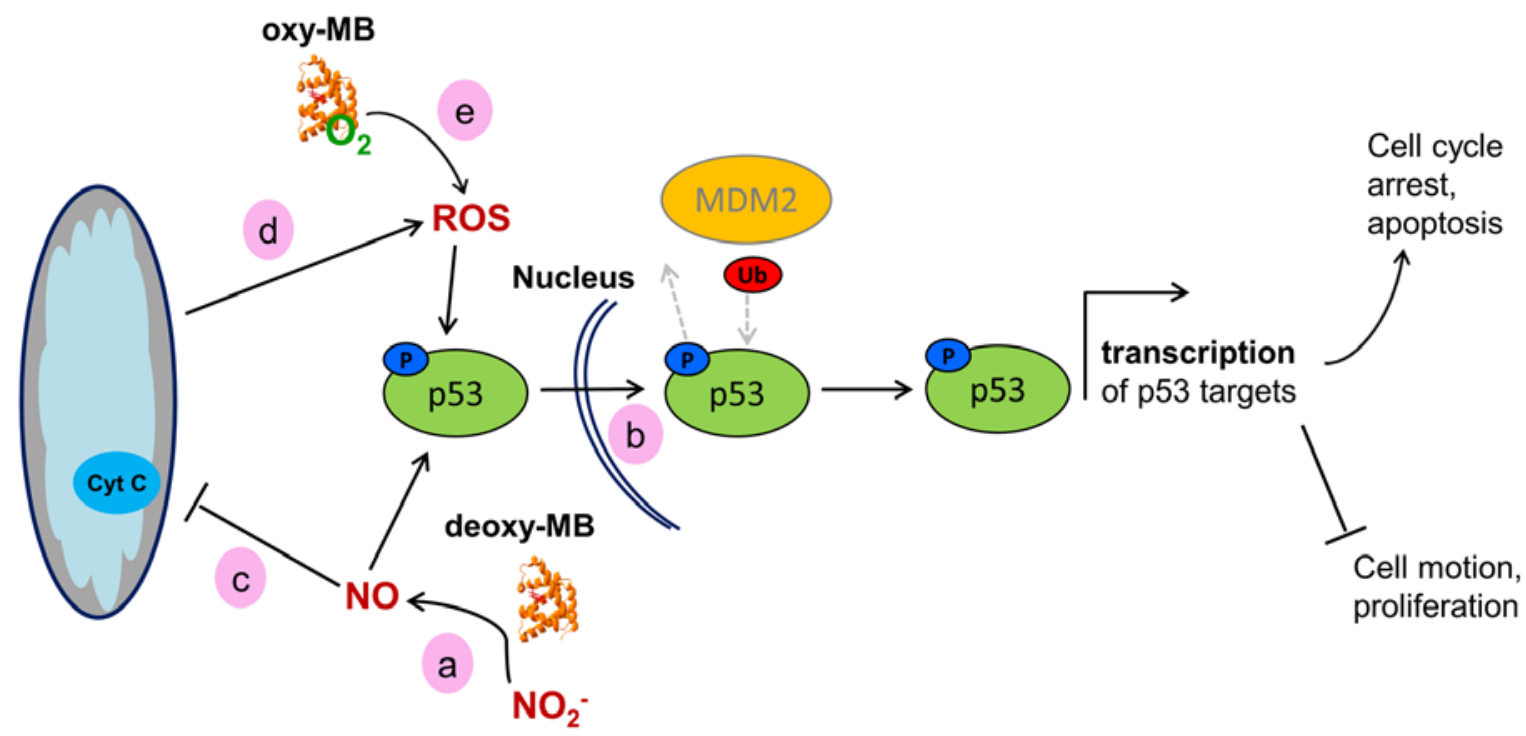

Figure 3. Working model of the hypothetical effects of MB on the activity of WT p53 in cancer cells. (a) Deoxy-MB may increase cellular NO levels to facilitate phosphorylation of p53. (b) Phosphorylated WT-p53 enters the nucleus and, unless ubiquitinated by MDM2, facilitates transcription of its target genes, resulting in a tumor-suppressor cell phenotype. (c) NO generated by deoxy-MB may inhibit the mitochondrial respiratory chain, (d) which would result in increased ROS levels. ROS could then affect p53 stabilization. (e) Oxy-MB may also release ROS under hypoxia and mediate p53 stabilization. MB, myoglobin; WT, wild-type; NO, nitric oxide; ROS, reactive oxygen species; MDM2, MDM2 proto-oncogene; Ub, ubiquitin; p, phosphorylated.

lactate dehydrogenase A (LDHA) gene and the glycolytic genes triosephospate isomerase 1 (TPII), GAPDH, protein kinase CGMP-dependent $1(P G K 1)$ and glycerol-3-phosphate acyltransferase, mitochondrial (GPAMI). By contrast, $M B$-knockdown in hypoxic colon cancer cells resulted in an increase in glycolytic flux, as LDHA and the glycolysis genes TPII, PGKI, GPAMI and enolase 1 were upregulated (Tables SI and SII).

In normoxic $M B$-knockdown breast cancer cells, the GO categories 'unsaturated fatty acid metabolic process' and 'unsaturated fatty acid biosynthetic process' were overrepresented in the set of downregulated genes (Table II), including fatty acid desaturase 3 and 84 -desaturase, sphingolipid 1
(Tables SI and SIII). By contrast, genes associated with sterol, cholesterol and steroid metabolic processes were upregulated in $M B$-knockdown breast cancer cells, such as sterol regulatory element binding transcription factor 1 (SREBF1), phosphomevalonate kinase, 24-dehydrocholesterol reductase (DHCR24) and cytochrome P450 1B1 (Tables SI and SIII). These results suggested that oxy-MB may stimulate the metabolism of unsaturated fatty acids in oxygenated breast cancer cells. However, the globin may also interfere with the synthesis of sterols.

In prostate cancer cells, si $M B$ treatment resulted in an increased ability to metabolize or synthetize fatty acids, 










sterols and eicosanoids, indicated by the upregulation of hydroxyacyl-CoA dehydrogenase trifunctional multienzyme complex $\beta, D H C R 24$, sterol-C5-desaturase, 15-hydroxyprostaglandin dehydrogenase $(H P G D)$, elongation of very long chain fatty acids protein 5 (ELOVL5) and acyl-CoA synthetase long chain family member 3 in normoxic si $M B$ cells, and by upregulation of ELOVL5, HPGD, fatty acid synthase and phospholipase A2 group $\mathrm{V}$ in si $M B$ hypoxic cells (Tables SI and SIII). By contrast, in hypoxic $M B$-knockdown colon cancer cells, the expression of genes associated with cholesterol and sterol metabolism and biosynthesis [DHCR7, 3-hydroxy-3-methylglutaryl-CoA synthase 1 (HMGCS1), farnesyl diphosphate synthase, farnesyl-diphosphate farnesyltransferase 1 and SREBF1] was decreased (Tables SI and SIII). In summary, the results of the transcriptome analysis suggested that MB may regulate fatty acid metabolism in a cell-type specific manner.

$M B$ expression is associated with apoptosis and migration. The GO categories 'induction of programmed cell death' and 'induction of apoptosis' were overrepresented in the set of downregulated genes in hypoxic $M B$-knockdown prostate cancer cells, suggesting that MB positivity may be associated with the stimulation of apoptotic processes in these cells. One option of maintaining apoptosis is by triggering cell cycle checkpoint signaling (36). Accordingly, in both normoxic and hypoxic siMB LNCaP cells, the GO categories 'regulation of cell cycle' and 'positive regulation of cell proliferation' were overrepresented among the downregulated genes, whereas the category 'negative regulation of cell proliferation' was enriched in the upregulated genes. In addition, the $G_{1} / S$ cell cycle checkpoint regulator cyclin-dependent kinase inhibitor 1a (CDKN1A, also termed TP21) was downregulated in $\operatorname{si} M B$ LNCaP cells. These results indicated direct or indirect involvement of $\mathrm{MB}$ in TP21 expression and a possible induction of cell cycle arrest in the presence of MB. However, this scenario is most probably of a more complex nature, since a subset of cell cycle progression-associated genes such as cyclin $\mathrm{B} 1(C C N B 1)$ and $C C N D 1$ were also downregulated in siMB LNCaP cells (Tables SI and SIII). Enrichment analyses also revealed that the GO categories 'cell motion' and 'cell migration' were significantly overrepresented among the upregulated genes of si $M B$ LNCaP cells (Table II), including activated leukocyte cell adhesion molecule, $C D 9, R A C 1$, laminin subunit $\gamma 1$ and thrombospondin (THBS1) under both $\mathrm{O}_{2}$ conditions (Tables SI and SIII). These observations strengthened our hypothesis that MB induced apoptosis and decreased the migratory and motion capacity of prostate cancer cells.

In breast cancer cells, genes associated with apoptosis were overrepresented in the sets of up- and downregulated MDA-MB468 cells under both $\mathrm{O}_{2}$ conditions (Table II), which made it difficult to discriminate the impact of $\mathrm{MB}$ on promoting or inhibiting apoptosis. The GO terms 'mitotic cell cycle', 'cell cycle process' and 'positive regulation of cell proliferation' were overrepresented in the downregulated genes of si $M B$ cells, whereas only a limited number of negative regulators of cell proliferation were upregulated (including retinoic acid receptor responder 3, prostaglandin $\mathrm{E}$ synthase and $C D K N 2 C$; Tables SI and SIII). These results may imply increased proliferation rates in MB-positive breast cancer cells. In addition, the GO terms 'cell motion' and 'cell migration' were significantly overrepresented in the downregulated genes of si $M B$ cells (Table II), as evidenced by the lower expression of THBS1, TNF receptor superfamily member 12A, vinculin, moesin and tensin 3 (Tables SI and SIII). Thus, the predictions made about the impact of MB on cell motion in hypoxic and normoxic breast cancer cells contradicted the results observed in prostate cancer cells.

In colon cancer cells, genes associated with apoptosis were also overrepresented in both up- and downregulated genes (Table II). The term 'cell cycle process' was overrepresented in the upregulated genes of hypoxic and normoxic siMB DLD-1 cells, including TPX2 microtubule nucleation factor, $C D C 20$, non-SMC condensin I complex subunit D2, family with sequence similarity 83 member D, $C C N B 1$ and $C C N B 2$. In addition, the term 'cell cycle arrest' was overrepresented in the downregulated genes of hypoxic si $M B$ samples (Table II) due to the downregulation of genes such as $C D K N 1 C, C D K N 1 A$, protein phosphatase 1 regulatory subunit $15 \mathrm{~A}$ and DNA damage inducible transcript 3 (Tables SI and SIII). Therefore, the DLD-1 data suggested that MB expression may mediate the suppression of cell cycle progression in colon cancer cells, possibly via apoptotic pathways.

In line with the results of the prostate cancer cell line, the GO term 'cell motion' was also overrepresented in the downregulated genes of normoxic siMB DLD-1 cells.

MB may impact on ROS and NO homeostasis in epithelial cancer cell lines. In hypoxic and normoxic $M B$-knockdown breast cancer cells, the GO term 'regulation of NO' biosynthetic process' and other GO categories referring to the biosynthetic process of $\mathrm{N}$-compounds were overrepresented in the downregulated genes, suggesting an increased production of NO in hypoxic and normoxic $M B$-positive breast cancer cells (Table SIII). This dependency between MB expression and $\mathrm{NO}^{-}$-related $\mathrm{GO}$ terms was also observed in prostate and colon cancer cells, which suggested involvement of $\mathrm{MB}$ in NO metabolism in all three cell types. All si $M B$ cells also exhibited enrichment of the GO category 'response to ROS' in the downregulated genes irrespective of the $\mathrm{O}_{2}$ culture conditions. Therefore, MB may be involved in increasing ROS levels in all tested cell lines.

$M B$ expression may affect the activity of key transcriptional regulators. To predict the differential activation of key transcriptional regulators in si $M B$ vs. $M B^{+}$cells, the mRNA expression of their target genes was examined using bioinformatic IPA upstream regulator analysis (Table III). A subset of 40 transcription factors was suggested to be differentially active in at least one cell line at hypoxia or normoxia, with high Z-scores indicating strong activation, and low Z-scores indicating transcription factor inhibition. All si $M B$ cells subjected to hypoxia and normoxic MDA-MB468 cells were predicted to exhibit decreased HIF1 $\alpha$ activity compared with the $\mathrm{MB}^{+}$controls. This was supported by the downregulation of HIF1 $\alpha$ target genes in the si $M B$ cell groups, including TP21 and nucleophosmin 1 in all cell lines, $L D H A$ in LNCaP and MDA-MB468 cells, aldolase fructose-bisphosphate A and interleukin 8 in MDA-MB468 and DLD-1 cells, vascular 
endothelial growth factor A in LNCaP cells and HIFlA, solute carrier family 2 member 1 and carbonic anhydrase 9 in MDA-MB468 cells (Table SI). Thus, MB may activate HIF1a in breast cancer cells and, to a lesser extent, in prostate and colon cancer cells.

IPA upstream activator analysis also suggested the involvement of p53 signaling in the three cancer cell lines (Table III). Of note, in our set up, only LNCaP cells encoded the TP53 wild-type-like Pro72Arg variant, whereas the MDA-MB468 and DLD-1 cells carried TP53 mutations Arg273His and Ser241Phe, respectively (Table SII), which affected the key residues of DNA-binding (37). RNA-Seq analysis of LNCaP cells demonstrated that $M B^{+}$was associated with the upregulation of p53 target genes including TP21, BCL2-interacting killer and heme oxygenase 1 (HMOXI) (Table SI), which suggested an activation of $\mathrm{p} 53$ signaling by $\mathrm{MB}$ in the prostate cancer model. In MDA-MB468 and DLD-1 cells expressing $M B$, even the mutant $\mathrm{p} 53$ was active, which was evidenced by the decreased expression of p63 target genes (Table III), possibly due to lowered $\mathrm{p} 63$ activity by the binding of mutated p53 $(38,39)$. Accordingly, IPA analysis results suggested activation of p63 in $M B^{+}$hypoxic $\mathrm{LNCaP}$ cells expressing the wild-type-like TP53 mutation Pro72Arg (Table III). Another fitting observation noted for the breast cancer cell line was enhanced transcriptional activity predicted for the oncogenic factor RELA (Table III), which is known to be activated by mutant p53 (40).

In line with the observed metabolic shifts in $M B^{+}$cancer cells, the gluconeogenesis and adipogenesis regulator forkhead box $\mathrm{O} 1$ was another transcription factor predicted to be dysregulated in the three cell models (Table II).

\section{Discussion}

The respiratory protein MB, known for its prominent presence in myocytes, is ectopically expressed in several cell types and malignancies, including tumors of the breast, prostate, lung, colon, kidney, bone, and head and neck (18-26).

Only a limited number of hypothesis-driven experiments have been conducted thus far to elucidate the role of MB in cancer cells $(28,41,42)$. The present study used the essentially unbiased approach of transcriptome analysis to reveal functional consequences of $M B$ expression vs. RNAi-mediated $M B$ knockdown in breast, prostate and colon cancer cells. Cells were cultured either at $1 \% \mathrm{O}_{2}$ or at room air conditions for $72 \mathrm{~h}$ to reflect long-term hypoxia-adapted, poorly vascularized hypoxic tumor areas and aerobic tissues with oxygenated MB (35). By Illumina transcriptome sequencing and bioinformatic read mapping, differentially expressed genes between $\operatorname{si} M B$ and $M B^{+}$cells were identified for all cell lines at either oxygen level. Gene lists were subjected to analyses of gene set enrichment to identify dysregulated biological processes and differentially active gene regulators and pathways. As a main observation, these results demonstrated increased cellular activity of HIF1 $\alpha$ signaling in $\mathrm{MB}^{+}$ vs. si $M B$ epithelial cancer cells; HIF1 $\alpha$ is the major transcription factor of the cellular hypoxia response (43). Multiple HIF1 $\alpha$ target genes were differentially expressed in all cell lines cultured under hypoxia, and respective GO-categories were enriched. Of note, comparatively less HIF $2 \alpha$ target genes were differentially expressed in $M B^{+}$vs. si $M B$ cells, although HIF $2 \alpha$ is generally considered to be more active following long-term hypoxia compared with HIF1a (44). Therefore, although hypoxia was applied for $72 \mathrm{~h}$, the function of MB may be associated with the differential expression of HIF1 $\alpha$ targets and may possibly be triggered by HIF1 $\alpha$ activity. Supporting hypothetical interaction between MB and HIF1 $\alpha$, a positive correlation of $M B$ mRNA or protein and HIF1 $\alpha$ target gene expression was reported in breast, prostate and non-small cell lung cancer $(21,22,24,29)$. MB levels were also increased in hypoxic, perinecrotic breast tumor regions (28). Additionally, in the present study, $M B$ expression was upregulated in LNCaP, MDA-MB468 and DLD-1 cells cultured under $1 \% \mathrm{O}_{2}$. This may be a result of HIF1 $\alpha$ binding to a candidate hypoxia response enhancer element $(27,28)$. Thus, transcription of $M B$ in tumor cells may be triggered by a HIF-dependent transactivation. Based on the present gene expression data, a working model may be proposed, linking the presence of MB to HIF1 $\alpha$ activity. A scheme of how this may be achieved is presented in Fig. 2. Deoxy-MB can produce NO through its nitrite reductase activity (12). This enzymatic activity may be active in the cancer cell models used in the present study, since the GO category ' $\mathrm{N}$-compound biosynthetic processes' was enriched in all $\mathrm{MB}^{+}$cells. NO inhibits the activity of the sensor protein prolyl-hydroxylase 2 (PHD2), which is the main PDH expressed in these cell models $(45,46)$. This would lead to diminished hydroxylation and increased stabilization of the HIF1 $\alpha$ protein, resulting in the increase of HIF1 $\alpha$ target gene transcription $(47,48)$, as observed in the present transcriptome data. Hypothetically, MB could counteract a fast decay of the HIF1 $\alpha$ response by constantly producing NO and decreasing PHD2 activity. As a formal alternative to this working model, MB may interfere with HIF1 $\alpha$ signaling by modulating intracellular ROS levels. The ferrous iron of PHD2 can be oxidized by $\mathrm{H}_{2} \mathrm{O}_{2}$, which prevents HIF1 $\alpha$ degradation and thus transiently increases HIF1 $\alpha$ activity $(49,50)$. Accordingly, the present transcriptome data demonstrated an overrepresentation of the GO category 'response to ROS' in all $M B^{+}$cells. In summary, MB may stabilize HIF1 $\alpha$ and support the hypoxia response in epithelial cancer cells, which may reduce the formation of hypoxic niches, resulting in a tumor-suppressing phenotype. Of note, the activity of PHD2 could, to a certain extent, be replaced by PHD1 and PHD3 (51). However, the PHD2 expression levels were mostly higher compared with those of PHD1 and PHD3 based on their RPKM values. In addition, a strong correlation of PHD2 and MB expression was previously reported in breast cancer (29), making it the prime candidate to potentially hydroxylate HIF1 $\alpha$ in an MB/NO-dependent manner. In agreement with the model established in the present study, MB-generated NO would simultaneously also inhibit PHD1 and PHD3 activity (45).

A second major result of the present transcriptome comparison of $M B^{+}$and si $M B$ cancer cells involved changes in metabolism. Breast and prostate $M B^{+}$cells revealed upregulation of genes involved in the energy-producing part of glycolysis and of $L D H A$, which converts pyruvate into L-lactate and regenerates $\mathrm{NAD}^{+}$from $\mathrm{NADH}^{+} \mathrm{H}^{+}$to sustain anaerobic substrate flux (52). This was in line with 
the enhanced HIF1 $\alpha$ signaling described above, since the upregulated genes are known HIF1 $\alpha$ targets (53). In contrast to the breast and prostate cancer cell lines, hypoxic $\mathrm{MB}^{+}$colon cancer cells exhibited downregulation of glycolysis-related genes and $L D H A$. GO term enrichment analyses of hypoxic colon cancer cells revealed that $\mathrm{MB}$ may contribute to enhanced cholesterol biosynthesis, previously described to occur in this cell type (54). HMGCS1, which induces cholesterol synthesis, was upregulated in $\mathrm{MB}^{+} \mathrm{DLD}-1$ cells, whereas FOXO1, a negative regulator of $H M G C S 1$ expression and thus cholesterol synthesis (55), was inactive. The involvement of MB in cholesterol metabolism appears to be unique to the colon cancer cell line cultured under hypoxia. By contrast, the breast cancer line indicated a specific contribution of $\mathrm{MB}$ to the metabolism of unsaturated fatty acids at normoxia, as indicated by enrichment of the associated GO terms. This supported previous in vitro studies demonstrating that oxy-MB was able to bind palmitic and oleic acid with physiological binding constants (13-15), potentially indicating a non-canonical role of the globin in the intracellular transport of unsaturated fatty acids. The observation that all three epithelial cancer cell line transcriptomes indicated different metabolic shifts in response to $M B$ knockdown suggests that additional cell type-specific properties need to be considered in order to understand the distinct metabolic role of $\mathrm{MB}$ in different cancer entities.

A third major finding of the present study was that the GO categories associated with negative or positive p53-mediated regulation of apoptosis and programmed cell death were overrepresented in all three $M B^{+}$cell lines. Since the three cell models differ in their p53 genotype, they require separate interpretation of the transcriptome data.

LNCaP prostate cancer cells express the wild-type-like TP53 mutation Pro72Arg, which has a higher binding affinity to 73 and thus an increased potential to induce apoptosis $(56,57)$. In the prostate cancer cell line, a multitude of p53 target genes were upregulated in $\mathrm{MB}^{+}$cells, including the elevated expression of the p53 target gene $T P 21$, which controls the $\mathrm{G}_{1} / \mathrm{S}$ cell cycle checkpoint and inhibits cell cycle progression (58). The activity of p21 is enhanced by increased ROS levels (59), as implicated by the results of the GO term enrichment. Elevated ROS levels, along with increased p53 activity, may trigger oxidative damage-induced cell death and, as a result, selectively kill cancer cells (60). As added indirect evidence for the presence of ROS in the present cell model, increased levels of $H M O X 1$ were observed in $\mathrm{MB}^{+} \mathrm{LNCaP}$; $H M O X 1$ is an enzyme that can be induced by oxidative stress and p53, and whose presence is also associated with cell cycle arrest and reduced cancer cell viability (60). This hypothetical p53/p21-mediated tumor-suppressing effect was further substantiated by the overrepresentation of GO categories associated with cell motion and migration in si $M B$ vs. $M^{+}$ cells. The transcriptome data of the prostate cancer model were thus in agreement with the ameliorated survival prognoses of patients with MB-positive prostate tumors (24). A hypothetical working model explaining the potential impact of MB on p53 activity is presented in Fig. 3.

As proposed previously in the HIF1 $\alpha$ scenario, deoxy-MB may enhance p53 action by producing NO in hypoxic
LNCaP cells which, in turn, could induce the phosphorylation of p53 $3^{\text {Pro72Arg }}$ and inhibit its nuclear export by MDM2 proto-oncogene, resulting in nuclear retention and subsequent activation (61). Augmentation of p53 $3^{\text {Pro72Arg }}$ signaling may further be maintained by stabilized HIF1 $\alpha$ or by increased ROS levels $(62,63)$, both of which may also be associated with the action of deoxy-MB (Fig. 3).

In contrast to the prostate cancer line, the breast cancer cell model MDA-MB468 encoded the gain-of-function TP53 mutation Arg273His, which impairs p53 target site binding (37). Despite the inability to directly drive p53 target gene expression, mutated p53 could function by interacting with other proteins. p53 ${ }^{\mathrm{Arg} 273 \mathrm{His}}$ may interact with and inactivate the tumor suppressor p63 (39) in the cell model used in the present study, as indicated by the observed downregulation of p63 target genes in $\mathrm{MB}^{+}$breast cancer cells. This may lead to enhanced cell survival and decreased apoptosis, which has been previously described in $T P 53^{\mathrm{Arg} 273 \mathrm{His}}$ vs. TP53-knockdown MDA-MB468 cells (38). In addition, mutated p53 may act as a co-factor of the RELA proto-oncogene/NF- $\kappa \mathrm{B}$ and STAT3 complex to induce the transcription of NF- $\mathrm{BB}$-regulated genes (40). The present transcriptome results suggested increased activity of p53 ${ }^{\mathrm{Arg} 273 \mathrm{His}}, \mathrm{RELA}$ and STAT3 in $\mathrm{MB}^{+}$breast cancer cells. Specifically for p53 ${ }^{\mathrm{Arg} 273 \mathrm{His}}$ expressing cell models, a tumor-promoting effect of MB may be hypothesized, which could be maintained, as proposed previously in terms of wild-type-like p53, by MB-mediated activation and stabilization of p5 $^{\mathrm{Arg} 273 \mathrm{His}}$ via increased cellular NO; ROS and HIF1 $\alpha$ levels (63).

In addition, GO-terms associated with cell migration, motion, and adhesion were enriched in the genes upregulated in $\mathrm{MB}^{+} \mathrm{MDA}-\mathrm{MB} 468$ cells. This finding was in agreement with a previous study, which revealed increased migratory potential, viability and proliferation rates in normoxia- and hypoxia-cultured $\mathrm{MB}^{+}$MDA-MB468 cells (28), thus experimentally validating our bioinformatics data. These in silico and in vitro results from the MDA-MB468 breast cancer cell model are contradictory to the beneficial prognostic outcome associated with MB positivity in breast tumors (21). However, the published Kaplan-Meier survival data lacked information about the patient p53 status. It may be speculated that the observed prognostic correlation mainly referred to wild-type-p53 cancer cases, but may result in the opposite outcome if analyzing the prognostic impact of $\mathrm{MB}$ in p53-gain-of-function mutated tumors. An alternative explanation is the strong positive correlation of MB with ER-expression in breast cancer, which itself is associated with better patient outcome. Of note, MB expression had additive prognostic value to ER alone, which raises the possibility of influences additional to the p53 status (21).

Transcription factor activity analyses also suggested p53 to be active in $\mathrm{MB}^{+}$DLD-1 colon cancer cells, which encoded the TP53 mutation Ser241Phe. Despite impaired target gene binding (37), p53 ${ }^{\text {Ser241Phe }}$ may also hypothetically function via interaction with other proteins. In analogy to MDA-MB468 cells, the predicted transcriptional activation of $R E L A$ in $M B^{+}, \mathrm{p} 53-$ mutated colon cancer cells suggested that the RELA/NF- $\kappa$ B/STAT3 complex may be active and participate in the transcription of NF- $\mathrm{BB}$ target genes (40). 
However, in contrast to a tumor-promoting role of MB in 53-mutated DLD-1 cells, upstream regulator analyses indicated significantly decreased activity of FOXM1 in $M B^{+}$ DLD-1 cells, possibly indicating increased $\mathrm{G}_{2} / \mathrm{M}$ arrest (64). In addition, the transcription factor FOXO3, which acts as a tumor suppressor by transcribing genes involved in cell cycle arrest and DNA repair (65), was predicted to be more active in $\mathrm{MB}^{+}$DLD-1 cells. FOXO3 can be trans-activated by HIF1 $\alpha$ and induced by metabolic stress and increased ROS levels (66), i.e., the conditions and transcription factors indicated to be active with $\mathrm{MB}$ expression. Although the differential activity of mutant p53 and RELA suggested tumor propagation by MB in DLD-1, the results also indicated that MB expression may indirectly intervene with cell cycle progression.

As an alternative scenario to a p53-driven cell cycle arrest, oxy-MB was recently reported to decrease cell proliferation by inducing mitochondrial fusion in p53-wild-type, as well as in p53-gain-of-function-mutated and p53-loss-of-function-mutated cell lines (42). In this network, oxy-MB was described to produce ROS, which increased parkin oxidation and inhibited the degradation of mitofusin 1 and 2. Thus, MB-positivity was linked to an increase in mitochondrial fusion, resulting in $\mathrm{G}_{1} / \mathrm{S}$ phase arrest. Although the results of the present study also demonstrated enrichment of genes associated with corresponding GO terms, the genes specifically involved in ROS/parkin-driven cell cycle arrest were not differentially expressed in any of the studied $\mathrm{MB}^{+}$vs. si $M B$ cell transcriptomes.

In summary, the present study performed the first transcriptome comparison of epithelial cancer cell models with endogenous vs. knocked-down levels of $M B$ mRNA expression. The results of the present study revealed distinct changes in gene expression following MB knockdown and suggested novel working hypotheses to integrate MB function into metabolic pathways and gene networks of epithelial cancer cells. Non-canonical enzymatic functions, which have previously been reported for MB in myocytes, seamlessly fit to explain a number of the present RNA-Seq results. Thus, important starting points were identified for future experimental work on the role of $\mathrm{MB}$ in tumors, e.g., by carefully considering the p53 status when choosing cell models. The proposed ability of MB to fine-tune levels of $\mathrm{NO}^{\circ}$ and ROS signaling molecules in epithelial cancer cells, if substantiated by further biochemical research, may significantly improve our understanding of cancer cell physiology.

\section{Acknowledgements}

Not applicable.

\section{Funding}

The present study was supported by Deutsche Forschungsgemeinschaft (grant no. Ha2103/10-1) and intramural grants by Johannes Gutenberg University Mainz (Stufe I) and the Johannes Gutenberg University Center for Computer Studies (CSM/SRFN). An Ingenuity Pathway Analysis license was provided by the Naturwissenschaftlich-medizinisches Forschungszentrum (NMFZ) and the University Medical Center Mainz. For cell culture, further financial support was received from von-Muralt Stiftung für Kleintiere, Switzerland.

\section{Availability of data and materials}

The datasets generated and analyzed during the current study are available in the EBI repository as study PRJEB31329 (https://www.ebi.ac.uk/ena/data/view/PRJEB31329).

\section{Authors' contributions}

$A B$ processed and analyzed the RNA-Seq and wrote the manuscript. TN analyzed the RNA-Seq data. DG and MAA conducted cell culture experiments. GK and JF inspected the data and revised the manuscript. TAG conducted cell culture experiments, inspected the data and revised the manuscript. $\mathrm{TH}$ interpreted the data and wrote the final manuscript. All authors read and approved the final manuscript.

\section{Ethics approval and consent to participate}

Not applicable.

\section{Patient consent for publication}

Not applicable.

\section{Competing interests}

The authors declare that they have no competing interests.

\section{References}

1. Mac Munn CA: VI. Researches on myohamatin and the histohæmatins. Phil. Trans. R. Soc 177: 267-298, 1886.

2. Millikan GA: Experiments on muscle hemoglobin in vivo; the instantaneous measurement of muscle metabolism. Proc R Soc Lond B 123: 218-241, 1937.

3. Wittenberg BA and Wittenberg JB: Transport of oxygen in muscle. Annu Rev Physiol 51: 857-878, 1989.

4. Wittenberg JB and Wittenberg BA: Myoglobin function reassessed. J Exp Biol 206: 2011-2020, 2003.

5. Endeward V, Gros G and Jürgens KD: Significance of myoglobin as an oxygen store and oxygen transporter in the intermittently perfused human heart: A model study. Cardiovasc Res 87: 22-29, 2010.

6. Gödecke A, Flögel U, Zanger K, Ding Z, Hirchenhain J, Decking UK and Schrader J: Disruption of myoglobin in mice induces multiple compensatory mechanisms. Proc Natl Acad Sci USA 96: 10495-10500, 1999

7. Grange RW, Meeson A, Chin E, Lau KS, Stull JT, Shelton JM, Williams RS and Garry DJ: Functional and molecular adaptations in skeletal muscle of myoglobin-mutant mice. Am J Physiol Cell Physiol 281: C1487-C1494, 2001.

8. Flögel U, Merx MW, Godecke A, Decking UK and Schrader J: Myoglobin: A scavenger of bioactive NO. Proc Natl Acad Sci USA 98: 735-740, 2001.

9. Flögel U, Gödecke A, Klotz LO and Schrader J: Role of myoglobin in the antioxidant defense of the heart. FASEB J 18: 1156-1158, 2004.

10. Helbo S, Dewilde S, Williams DR, Berghmans H, Berenbrink M, Cossins AR and Fago A: Functional differentiation of myoglobin isoforms in hypoxia-tolerant carp indicates tissue-specific protective roles. Am J Physiol Regul Integr Comp Physiol 302: R693-R701, 2012.

11. Schlater AE, De Miranda MA Jr, Frye MA, Trumble SJ and Kanatous SB: Changing the paradigm for myoglobin: A novel link between lipids and myoglobin. J Appl Physiol (1985) 117: 307-315, 2014. 
12. Hendgen-Cotta UB, Kelm M and Rassaf T: Myoglobin's novel role in nitrite-induced hypoxic vasodilation. Trends Cardiovasc Med 24: 69-74, 2014.

13. Sriram R, Kreutzer U, Shih L and Jue T: Interaction of fatty acid with myoglobin. FEBS Lett 582: 3643-3649, 2008.

14. Shih L, Chung Y, Sriram R and Jue T: Interaction of myoglobin with oleic acid. Chem Phys Lipids 191: 115-122, 2015.

15. Chintapalli SV, Jayanthi S, Mallipeddi PL, Gundampati R, Suresh Kumar TK, van Rossum DB, Anishkin A and Adams SH: Novel molecular interactions of acylcarnitines and fatty acids with myoglobin. J Biol Chem 291: 25133-25143, 2016.

16. Flögel U, Laussmann T, Gödecke A, Abanador N, Schäfers M, Fingas CD, Metzger S, Levkau B, Jacoby C and Schrader J: Lack of myoglobin causes a switch in cardiac substrate selection. Circ Res 96: e68-e75, 2005.

17. Hendgen-Cotta UB, Esfeld S, Coman C, Ahrends R, Klein-Hitpass L, Flögel U, Rassaf T and Totzeck M: A novel physiological role for cardiac myoglobin in lipid metabolism. Sci Rep 7: 43219, 2017.

18. Ruck P,Horny HP, Greschniok A, Wehrmann M and Kaiserling E: Nonspecific immunostaining of blast cells of acute leukemia by antibodies against nonhemopoietic antigens. Hematol Pathol 9: 49-56, 1995.

19. Zhang PJ, Goldblum JR, Pawel BR, Fisher C, Pasha TL and Barr FG: Immunophenotype of desmoplastic small round cell tumors as detected in cases with EWS-WT1 gene fusion product. Mod Pathol 16: 229-235, 2003

20. Flonta SE, Arena S, Pisacane A, Michieli P and Bardelli A Expression and functional regulation of myoglobin in epithelial cancers. Am J Pathol 175: 201-206, 2009.

21. Kristiansen G, Rose M, Geisler C, Fritzsche FR, Gerhardt J, Lüke C, Ladhoff AM, Knüchel R, Dietel M, Moch H, et al: Endogenous myoglobin in human breast cancer is a hallmark of luminal cancer phenotype. Br J Cancer 102: 1736-1745, 2010.

22. Oleksiewicz U, Daskoulidou N, Liloglou T, Tasopoulou K, Bryan J, Gosney JR, Field JK and Xinarianos G: Neuroglobin and myoglobin in non-small cell lung cancer: Expression, regulation and prognosis. Lung Cancer 74: 411-418, 2011.

23. Behnes CL, Bedke J, Schneider S, Küffer S, Strauss A, Bremmer F, Ströbel P and Radzun HJ: Myoglobin expression in renal cell carcinoma is regulated by hypoxia. Exp Mol Pathol 95 307-312, 2013.

24. Meller S, Bicker A, Montani M, Ikenberg K, Rostamzadeh B, Sailer V, Wild P, Dietrich D, Uhl B, Sulser T, et al: Myoglobin expression in prostate cancer is correlated to androgen receptor expression and markers of tumor hypoxia. Virchows Arch 465 419-427, 2014

25. Meller S, VAN Ellen A, Gevensleben H, Bicker A, Hankeln T, Gorr TA, Sailer V, Dröge F, Schröck F, Bootz F, et al: Ectopic myoglobin expression is associated with a favourable outcome in head and neck squamous cell carcinoma patients. Anticancer Res 36: 6235-6241, 2016

26. Bicker A, Dietrich D, Gleixner E, Kristiansen G, Gorr TA and Hankeln T: Extensive transcriptional complexity during hypoxia-regulated expression of the myoglobin gene in cancer. Hum Mol Genet 23: 479-490, 2014

27. Bicker A, Brahmer AM, Meller S, Kristiansen G, Gorr TA and Hankeln T: The distinct gene regulatory network of myoglobin in prostate and breast cancer. PLoS One 10: e0142662, 2015.

28. Kristiansen G, Hu J, Wichmann D, Stiehl DP, Rose M, Gerhardt J, Bohnert A, ten Haaf A, Moch H, Raleigh J, et al: Endogenous myoglobin in breast cancer is hypoxia-inducible by alternative transcription and functions to impair mitochondrial activity: A role in tumor suppression? J Biol Chem 286: 43417-43428, 2011.

29. Gorr TA, Wichmann D, Pilarsky C, Theurillat JP, Fabrizius A, Laufs T, Bauer T, Koslowski M, Horn S, Burmester T, et al: Old proteins - new locations: Myoglobin, haemoglobin, neuroglobin and cytoglobin in solid tumours and cancer cells. Acta Physiol (Oxf) 202: 563-581, 2011

30. Mortazavi A, Williams BA, McCue K, Schaeffer L and Wold B: Mapping and quantifying mammalian transcriptomes by RNA-Seq. Nat Methods 5: 621-628, 2008.

31. Kal AJ, van Zonneveld AJ, Benes V, van den Berg M, Koerkamp MG, Albermann K, Strack N, Ruijter JM, Richter A, Dujon B, et al: Dynamics of gene expression revealed by comparison of serial analysis of gene expression transcript profiles from yeast grown on two different carbon sources. Mol Biol Cell 10: 1859-1872, 1999.

32. Maere S, Heymans K and Kuiper M: BiNGO: A Cytoscape plugin to assess overrepresentation of gene ontology categories in biological networks. Bioinformatics 21: 3448-3449, 2005.
33. Huang da W, Sherman BT and Lempicki RA: Systematic and integrative analysis of large gene lists using DAVID bioinformatics resources. Nat Protoc 4: 44-57, 2009.

34. Huang da W, Sherman BT and Lempicki RA: Bioinformatics enrichment tools: Paths toward the comprehensive functional analysis of large gene lists. Nucleic Acids Res 37: 1-13, 2009.

35. Totzeck M, Hendgen-Cotta UB, Kelm M and Rassaf T: Crosstalk between nitrite, myoglobin and reactive oxygen species to regulate vasodilation under hypoxia. PLoS One 9: e105951, 2014.

36. Vousden KH and Prives C: Blinded by the light: The growing complexity of p53. Cell 137: 413-431, 2009.

37. Saha T, Kar RK and Sa G: Structural and sequential context of p53: A review of experimental and theoretical evidence. Prog Biophys Mol Biol 117: 250-263, 2015.

38. Lim LY, Vidnovic N, Ellisen LW and Leong CO: Mutant p53 mediates survival of breast cancer cells. $\mathrm{Br} \mathrm{J}$ Cancer 101: 1606-1612, 2009.

39. Muller PA, Vousden KH and Norman JC: p53 and its mutants in tumor cell migration and invasion. J Cell Biol 192: 209-218 2011.

40. Choy MK, Movassagh M, Siggens L, Vujic A, Goddard M, Sánchez A, Perkins N, Figg N, Bennett M, Carroll J and Foo R: High-throughput sequencing identifies STAT3 as the DNA-associated factor for p53-NF-kappaB-complex-dependent gene expression in human heart failure. Genome Med 2: 37, 2010.

41. Galluzzo M, Pennacchietti S, Rosano S, Comoglio PM and Michieli P: Prevention of hypoxia by myoglobin expression in human tumor cells promotes differentiation and inhibits metastasis. J Clin Invest 119: 865-875, 2009.

42. Braganza A, Quesnelle K, Bickta J, Reyes C, Wang Y, Jessup M, St Croix C, Arlotti J, Singh SV and Shiva S: Myoglobin induces mitochondrial fusion, thereby inhibiting breast cancer cell proliferation. J Biol Chem 294: 7269-7282, 2019.

43. Wang GL, Jiang BH, Rue EA and Semenza GL: Hypoxia-inducible factor 1 is a basic-helix-loop-helix-PAS heterodimer regulated by cellular O2 tension. Proc Natl Acad Sci USA 92: 5510-5514, 1995.

44. Stiehl DP, Bordoli MR, Abreu-Rodríguez I, Wollenick K, Schraml P, Gradin K, Poellinger L, Kristiansen $G$ and Wenger RH: Non-canonical HIF-2 $\alpha$ function drives autonomous breast cancer cell growth via an AREG-EGFR/ErbB4 autocrine loop. Oncogene 31: 2283-2297, 2012.

45. Metzen E, Zhou J, Jelkmann W, Fandrey J and Brüne B: Nitric oxide impairs normoxic degradation of HIF-1alpha by inhibition of prolyl hydroxylases. Mol Biol Cell 14: 3470-3481, 2003.

46. Berchner-Pfannschmidt U, Yamac H, Trinidad B and Fandrey J: Nitric oxide modulates oxygen sensing by hypoxia-inducible factor 1-dependent induction of prolyl hydroxylase 2. J Biol Chem 282: 1788-1796, 2007.

47. Depping R, Steinhoff A, Schindler SG, Friedrich B, Fagerlund R, Metzen E, Hartmann E and Köhler M: Nuclear translocation of hypoxia-inducible factors (HIFs): Involvement of the classical importin alpha/beta pathway. Biochim Biophys Acta 1783: 394-404, 2008.

48. Berchner-Pfannschmidt U, Tug S, Kirsch M and Fandrey J: Oxygen-sensing under the influence of nitric oxide. Cell Signal 22: 349-356, 2010

49. Hagen T: Oxygen versus reactive oxygen in the regulation of HIF-1 $\alpha$ : The balance tips. Biochem Res Int 2012: 436981, 2012.

50. Niecknig H, Tug S, Reyes BD, Kirsch M, Fandrey J and Berchner-Pfannschmidt U: Role of reactive oxygen species in the regulation of HIF-1 by prolyl hydroxylase 2 under mild hypoxia. Free Radic Res 46: 705-717, 2012.

51. Appelhoff RJ, Tian YM, Raval RR, Turley H, Harris AL Pugh CW, Ratcliffe PJ and Gleadle JM: Differential function of the prolyl hydroxylases PHD1, PHD2, and PHD3 in the regulation of hypoxia-inducible factor. J Biol Chem 279: 38458-38465, 2004.

52. Rossignol R, Gilkerson R, Aggeler R, Yamagata K, Remington SJ and Capaldi RA: Energy substrate modulates mitochondrial structure and oxidative capacity in cancer cells. Cancer Res 64: 985-993, 2004.

53. Semenza GL, Roth PH, Fang HM and Wang GL: Transcriptional regulation of genes encoding glycolytic enzymes by hypoxia-inducible factor 1. J Biol Chem 269: 23757-23763, 1994.

54. Notarnicola M, Messa C, Pricci M, Guerra V, Altomare DF, Montemurro S and Caruso MG: Up-regulation of 3-hydroxy-3-methylglutaryl coenzyme A reductase activity in left-sided human colon cancer. Anticancer Res 24: 3837-3842, 2004. 
55. Liu Z, Rudd MD, Hernandez-Gonzalez I, Gonzalez-Robayna I, Fan HY, Zeleznik AJ and Richards JS: FSH and FOXO1 regulate genes in the sterol/steroid and lipid biosynthetic pathways in granulosa cells. Mol Endocrinol 23: 649-661, 2009.

56. Marin MC, Jost CA, Brooks LA, Irwin MS, O'Nions J, Tidy JA, James N, McGregor JM, Harwood CA, Yulug IG, et al: A common polymorphism acts as an intragenic modifier of mutant p53 behaviour. Nat Genet 25: 47-54, 2000.

57. Dumont P, Leu JI, Della Pietra AC III, George DL and Murphy M: The codon 72 polymorphic variants of p53 have markedly different apoptotic potential. Nat Genet 33: 357-365, 2003.

58. Deng C, Zhang P, Harper JW, Elledge SJ and Leder P: Mice lacking p21CIP1/WAF1 undergo normal development, but are defective in G1 checkpoint control. Cell 82: 675-684, 1995.

59. Vurusaner B, Poli G and Basaga H: Tumor suppressor genes and ROS: Complex networks of interactions. Free Radic Biol Med 52: 7-18, 2012.

60. Andrés NC, Fermento ME, Gandini NA, Romero AL, Ferro A, Donna LG, Curino AC and Facchinetti MM: Heme oxygenase-1 has antitumoral effects in colorectal cancer: Involvement of p53. Exp Mol Pathol 97: 321-331, 2014.

61. Wang X, Zalcenstein A and Oren M: Nitric oxide promotes p53 nuclear retention and sensitizes neuroblastoma cells to apoptosis by ionizing radiation. Cell Death Differ 10: 468-476, 2003.
62. Chen D, Li M, Luo J and Gu W: Direct interactions between HIF-1 alpha and Mdm2 modulate p53 function. J Biol Chem 278: 13595-13598, 2003.

63. Sermeus A and Michiels C: Reciprocal influence of the p53 and the hypoxic pathways. Cell Death Dis 2: e164, 2011.

64. Gartel AL: FOXM1 in cancer: Interactions and vulnerabilities. Cancer Res 77: 3135-3139, 2017.

65. Renault VM, Thekkat PU, Hoang KL, White JL, Brady CA, Kenzelmann Broz D, Venturelli OS, Johnson TM, Oskoui PR, Xuan Z, et al: The pro-longevity gene FoxO3 is a direct target of the p53 tumor suppressor. Oncogene 30: 3207-3221, 2011

66. Klotz LO, Sánchez-Ramos C, Prieto-Arroyo I, Urbánek P, Steinbrenner $\mathrm{H}$ and Monsalve $\mathrm{M}$ : Redox regulation of FoxO transcription factors. Redox Biol 6: 51-72, 2015.

This work is licensed under a Creative Commons Attribution-NonCommercial-NoDerivatives 4.0 International (CC BY-NC-ND 4.0) License. 